Volume: 1, Issue: 4, December 2016, Pages: 84-87, DOI: http://dx.doi.org/10.19082/ah87

\title{
USE OF THE INTERNAL THORACIC ARTERY TO GRAFT AN ANOMALOUS LEFT MAIN CORONARY ARTERY FROM THE PULMONARY ARTERY IN A FIVE-YEAR-OLD GIRL
}

\author{
Ahmad Takriti ${ }^{1}$, Firas Alakhras Aljanadi ${ }^{2}$
}

1: CES., DES., Professor of Cardiac Surgery and Chief of Cardiac Surgery Department, Faculty of Medicine, Damascus University Cardiac Surgery Hospital, Damascus, Syria

2: M.D., MSc., Damascus University Cardiac Surgery Hospital, Damascus University, Damascus, Syria

\section{TYPE OF ARTICLE: CASE REPORT}

\begin{abstract}
Introduction: Anomalous left coronary artery from the pulmonary artery (ALCAPA) is a rare congenital cardiac malformation in which the left coronary artery arises from the pulmonary artery. It usually presents during the first months of life with features of myocardial ischemia or heart failure. It is potentially fatal with a high mortality rate in the first year of life; however, the prognosis is good with early surgical correction.

Case Presentation: We report a five-year-old female presented with exertional chest pain, dyspnea, and palpitation. Echocardiography and coronary angiography revealed an anomalous left coronary artery arising from the pulmonary artery with mitral regurgitation. She underwent successful surgery to establish a dual-coronary system, where the left internal thoracic (mammary) artery was used to revascularise the left coronary artery with mitral valve repair. Excellent surgical results were obtained, and the patient was discharged from the hospital without complaints, and the five-year follow-up proved the efficacy of such technique.

Conclusion: Using the internal thoracic artery as a graft is an alternative for the treatment of anomalous origin of the left coronary artery from the pulmonary artery in children when re-implantation is not feasible.

KEYWORDS: Coronary vessel, Anomalies, Left coronary artery, Mitral regurgitation, Internal thoracic artery
\end{abstract}

\section{INTRODUCTION}

Anomalous left coronary artery from the pulmonary artery (ALCAPA) is a rare congenital anomaly, which, if left unrepaired, has a mortality rate up to $90 \%(1,2)$. Left ventricular (LV) dysfunction and ischemic mitral regurgitation (MR) secondary to mitral annular dilatation and ischemic papillary muscle dysfunction contributes to the morbidity and mortality in this condition (2). However, early surgical correction by establishing a two-coronary system after diagnosis provides the best results and leads progressively to almost total myocardial recovery (3). Direct reimplantation of the ALCAPA can be sometimes anatomically difficult. In such cases, coronary artery bypass grafting using the internal thoracic artery might be considered a judicious choice (3). Fortune and associates suggested the use of the left internal thoracic artery (ITA) as a bypass graft in children (3) for the first time in 1987. Because there has been a limited number of reports regarding the use of ITA grafts for the treatment of congenital malformations of the coronary arteries (4), we herein describe a case of a five-year-old girl with ALCAPA, treated by using the internal thoracic artery to graft the left main coronary artery to establish a dual coronary system.

\section{CASE PRESENTATION}

\subsection{Patient's Characteristics}

A five-year-old girl presented with an exertional dyspnea progressed throughout the last two months accompanied with exertional chest pain and palpitations. There was no significant personal or family history.

\section{Correspondence:}

Dr. Firas Alakhras Aljanadi, Damascus University Cardiac Surgery Hospital, Damascus University, Damascus, Syria. Tel: +44.7405163591, Email: firasaljanadi@gmail.com

Received: November 2, 2016, Accepted: November 18, 2016, Published: December 2016

iThenticate screening: November 4, 2016, English editing: November 24, 2016, Quality control: November 29, 2016 (C) 2016 The Authors. This is an open access article under the terms of the Creative Commons Attribution-NonCommercialNoDerivs License, which permits use and distribution in any medium, provided the original work is properly cited, the use is non-commercial and no modifications or adaptations are made. 


\subsection{Physical examination}

On physical examination, there was no abnormal face or cyanosis. There was tachycardia 160 beats/min, tachypnea with 28 breaths/min, O2 saturation $94 \%$, and blood pressure of $148 / 90 \mathrm{mmHg}$. On auscultation, there was fine crackles heard at the lung bases and systolic murmur at the apex grading $3 / 6$. The electrocardiogram showed sinus tachycardia with signs of anterior-lateral ischemia, left atrium dilation, and left ventricle dilation. Lab tests were within normal.

\subsection{Imaging findings}

The chest $\mathrm{x}$-ray revealed cardiomegaly while the preoperative echocardiography showed dilated left ventricle (LVEDD - LVESD: $45.5 \mathrm{~mm}-33.8 \mathrm{~mm}$ ) with mitral valve regurgitation $3 / 4$, ejection fraction of $35 \%$ with anteriorlateral and septal wall motion abnormalities (Figure 1). Cardiac catheterization revealed a dilated right coronary artery $(5 \mathrm{~mm})$ with few collaterals connecting it with the left coronary artery, which has anomalous origin from the pulmonary artery trunk (ALCAPA) (Figure 2).

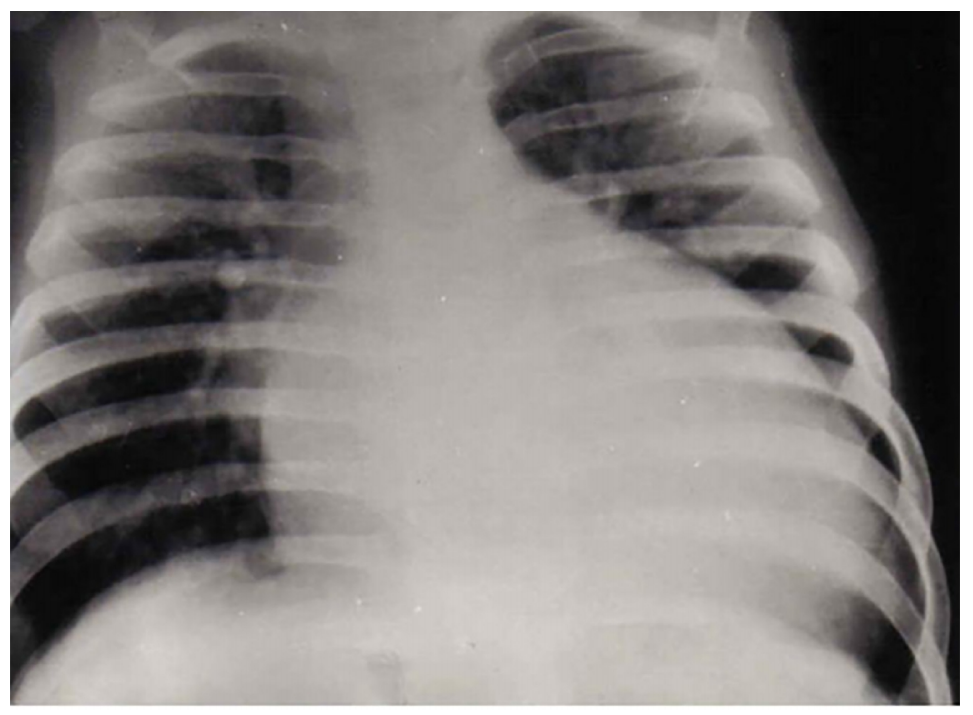

Figure 1. Chest x-ray shows cardiomegaly with significant dilated left chambers.

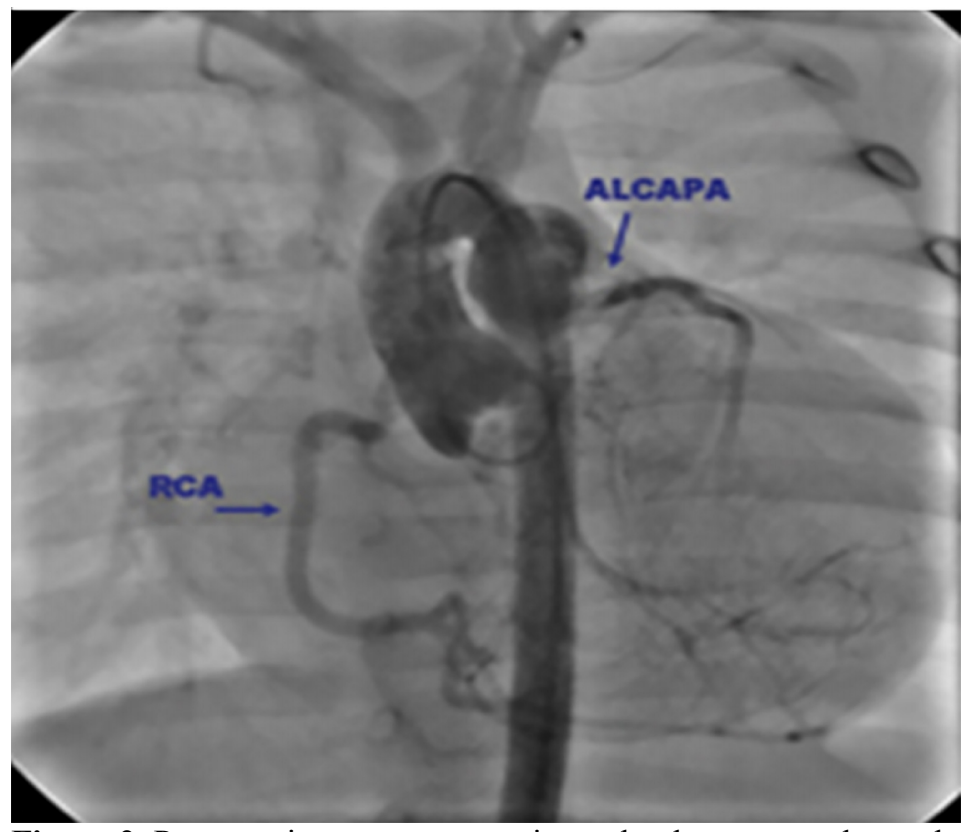

Figure 2. Preoperative coronary arteriography demonstrated an enlarged right coronary artery with few collaterals to the left coronary artery, eventually draining into the pulmonary artery. 


\subsection{Treatment}

On the basis on these findings of severe mitral valve regurgitation and ALCAPA, surgery was indicated, which was done under general anesthesia through a midline sternotomy. After cardiopulmonary bypass (CPB) was set with standard aortic and bicaval venous cannulation; the left ventricle was vented through the right superior pulmonary vein, and mild hypothermia $\left(32^{\circ}\right.$ to $\left.34^{\circ}\right)$ was maintained. Once CPB was initiated, the aorta was cross-clamped, and the heart was arrested with antegrade blood cardioplegia infused into the ascending aorta while simultaneously occluding the ALCAPA at its pulmonary origin or by occluding the main pulmonary trunk. After the heart was arrested, the left atrium was incised and the mitral valve was tested and found severely regurgitant; a posterior commissuroplasty was done, and, after it was tested and found competent, the left atriotomy was closed after air was removed from the left side of the heart. We found the left main coronary artery arises from main pulmonary artery, and, through an incision made in the pulmonary trunk, we noticed that the anomalous orifice was arising deeply in the non-facing sinus of the pulmonary valve, and this orifice was so close to the commissure with the left posterior facing sinus; after a short distance, it divided into the left anterior descending (LAD) and the circumflex arteries. We also noticed that the right coronary artery was dilated and tortuous. Actually, operation was scheduled at first to perform re-implantation of the left coronary artery to the aorta; however, the unfavorable anatomy and the significant distance between the origin of the left main coronary artery and the aorta made re-implantation on the aorta unachievable. In addition to that, the pulmonary artery was small and the orifice of the left main artery was deep in the sinus, which might interfere with and impair the pulmonary valve when creating intrapulmonary tunnel (Takeuchi procedure). Furthermore, the collaterals between the left and right coronary circulations do not assure the aimed outcome if the left coronary artery was ligated. Because of all these aspects, we proceeded with using the left internal thoracic artery, which was mobilized, harvested, and implanted at the beginning of the left main coronary artery with end-to-side anastomosis, after detecting the left main course using a probe entered through the anomalous orifice. Afterward, through the pulmonary incision, the orifice of the anomalous origin of the left coronary artery was closed directly, to avoid eventual competitive flow, and the arteriotomy was closed. The aortic cross-clamp was released, the heart started beating in a sinus rhythm without ischemia signs on the ECG, with uneventful weaning from CBP, and echocardiography showed a trivial mitral regurgitation, the sternum was close primarily and the child was transferred to the ICU.

\subsection{Outcome and follow-up}

Post-operative echocardiography confirmed the same result with good left and right ventricle contractility and no regional wall motion abnormalities. The little girl was discharged home on the fifth postoperative day without complaints. Throughout the follow-up for five years, the patient was asymptomatic, within normal physical examination and the echo showing an ejection fraction of $74 \%$, trivial mitral regurgitation (MR), and normal left ventricular dimensions with no dyskinesia. As the patient was asymptomatic, no routine coronary angiography was performed.

\section{DISCUSSION}

Surgical management is the gold standard in the therapy of ALCAPA and has developed considerably since the first trials (3). Operative approaches that establish a dual coronary supply to the heart have been associated with improved outcomes compared with approaches that result in one source for coronary circulation (5). In our patient, ALCAPA ligation was never considered as a choice due to reduced long-term survival and high mortality, which reaches $50 \%$ (3). Re-implantation was not pliable, as the anomalous orifice of ALCAPA was so deep arising from the non-facing sinus and close to the commissure with the posterior left sinus. While some authors suggested that detachment of the commissure between the posterior and the non-coronary sinuses was often necessary in such cases (5); however, because of the unfavorable coronary anatomy and lack of length, we did not prefer to detach the commissure and leaflets, as that may damage the pulmonary valve, and this may need a long follow-up to show its effects (5). Due to the same reasons, there was difficulty in doing the Takeuchi procedure without also doing detachment of the commissure and the leaflets. In addition, the Takeuchi procedure holds probable complications, including varying degrees of supravalvular pulmonary stenosis, baffle leaks creating a coronary-PA fistula, and aortic valve insufficiency (3). Because the ITA has a potential for circumferential as well as longitudinal development according to coronary flow requirements and patient growth, we have the same belief as other authors that the ITA is the best graft material for the treatment of congenital coronary artery abnormalities requiring bypass operation in children (4). In general, using surgical techniques that aim to establish a two-coronary system, as we used the ITA for this purpose in our case, leads to return the dilated RCA to its previous size, and it was observed that intracoronary collaterals had regressed (3). There was no difference between different surgical techniques that re-establish a two-coronary system regarding the long-term LV function or late mortality (3). Reduced long-term 
survival was only associated with isolated ALCAPA ligation, which does not normalize LV volume or ejection fraction (3). Any surgical technique creating a two-coronary system will result in recovery of ischemic but viable myocardium, as proved by stress thallium 201 and dipyridamole stress echocardiography, which elucidates the significant postoperative improvement in the LV function within days (3). Regarding mitral valve repair, though several studies reported that it increases aortic cross-clamp time on an already ischemic myocardium (2), we recommend routine repair of a structurally defective mitral valve at the time of coronary artery revascularization on the grounds that it can be undertaken safely and with good results and because $50 \%$ of patients with severe MR who did not undergo concomitant MV repair had late MV operation (2). Generally, all patients should be followed-up to assess the efficacy of correction and to rule out ongoing or recurrent myocardial ischemia (3).

\section{CONCLUSIONS}

A diagnosis of ALCAP was established in a five-year-old girl, presented with exertional dyspnea, palpitatio and chest pain, by cardiac catheterization. The main goal of surgical treatment of ALCAPA is to establish a dual coronary system, typically by doing a left coronary translocation by the various available techniques; however, using the internal thoracic artery as a graft is an alternative for the treatment of anomalous origin of the left coronary artery from the pulmonary artery in children when re-implantation is not feasible. Follow-up for five years proved the substantial improvement in LV function; however, further follow-up is required to establish the long-term efficacy of this therapeutic approach.

\section{ACKNOWLEDGMENTS:}

The authors would like to thank the surgical, anesthetic, and theatre staff at Damascus University Cardiac Surgery Hospital for their co-operation and forbearance.

\section{CONFLICT OF INTEREST:}

There is no conflict of interest to be declared.

\section{AUTHORS' CONTRIBUTIONS:}

All authors contributed to this project and article equally. All authors read and approved the final manuscript.

\section{REFERENCES:}

1) Wesselhoeft H, Fawcett JS, Johnson AL. Anomalous origin of the left coronary artery from the pulmonary trunk. Circulation. 1968; 38 (2): 403-25. doi :10.1161/01.CIR.38.2.403.

2) Naimo PS, Fricke TA, d'Udekem Y, Cochrane AD, Bullock A, Robertson T, Brizard CP, Konstantinov IE. Surgical intervention for anomalous origin of left coronary artery from the pulmonary artery in children: a long-term follow-up. The Annals of thoracic surgery. 2016; 101(5): 1842-8. doi:10.1016/j.athoracsur.2015.11.020. PMid: 26897320.

3) Dodge-Khatami A, Mavroudis C, Backer CL. Anomalous origin of the left coronary artery from the pulmonary artery: collective review of surgical therapy. The Annals of Thoracic Surgery. $2002 ; 74$ (3): 946-55. doi: 10.1016/S0003-4975 (02)03633-0. PMid: 12238882.

4) Kitamura S, Kawachi K, Nishii T, Taniguchi S, Inoue K, Mizuguchi K, Fukutomi M. Internal thoracic artery grafting for congenital coronary malformations. The Annals of thoracic surgery. 1992; 53 (3): $513-6$. doi: 10.1016/0003-4975 (92)90283-A.

5) Alsoufi B, Sallehuddin A, Bulbul Z, Joufan M, Khouqeer F, Canver CC, Kalloghlian A, Al-Halees Z. Surgical strategy to establish a dual-coronary system for the management of anomalous left coronary artery origin from the pulmonary artery. The Annals of thoracic surgery. 2008; 86 (1): 170-6. doi: 10.1016/j.athoracsur.2008.03.032 . PMid: 18573418. 